\title{
Sistem Informasi Manajemen Hubungan Pelanggan Berbasis Web Pada PT. Arya Media Tour \& Travel
}

\author{
Ahmad Azizul Hakim*1, Singgi Pratama ${ }^{2}$, Fransiska Prihatini $\mathrm{S}^{\mathbf{3}}$ \\ ${ }^{123}$ STMIK GI MDP; Jl. Rajawali No.14 Palembang, Telp(0711)376400 \\ Program Studi Sistem Informasi, STMIK GI MDP, Palembang \\ e-mail: ${ }^{1}$ hakim.ahmadazizul@mhs.mdp.ac.id, ${ }^{2}$ singgipratama@mhs.mdp.ac.id, \\ ${ }^{3}$ fransiskaps@mhs.mdp.ac.id
}

\begin{abstract}
Abstrak
Tour \& Travel merupakan perusahaan yang bergerak di bidang jasa dan pelayanan pariwisata di dalam dan layanan luar negeri, pemesanan tiket pesawat, pemesanan hotel, rental mobil, dan layanan haji/umroh. Perusahaan ini mengalami keterbatasan media informasi promosi, akibatnya pelanggan kurang mengetahui informasi secara lengkap dan benar. Selain itu perusahaan ini dapat melakukan kustomisasi, akan tetapi pelanggan tidak banyak yang mengetahui hal tersebut. Keluhan pelanggan selama perjalanan sering kali tidak sampai langsung ke direktur, akan tetapi pelanggan selalu menyampaikannya ke tourguide. Pembangunan aplikasi untuk mengatasi masalah tersebut yaitu membangun sistem informasi manajemen hubungan pelanggan berbasis website dengan metode yang digunakan adalah metodologi iterasi yang terdiri dari fase perencanaan, fase analisis masalah, fase perancangan, fase implementasi, dan fase pemeliharaan. Aplikasi ini menggunakan bahasa pemograman PHP dan menggunakan program Notepad++ serta MySQL sebagai basis data. Dengan adanya aplikasi ini dapat membantu dalam penyampaian informasi serta membantu perusahaan dalam meningkatkan loyalitas pelanggan, menarik pelanggan baru dan mempertahankan pelanggan yang telah ada agar dapat membantu setiap proses pemasaran yang dilakukan oleh perusahaan.
\end{abstract}

Kata kunci : Sistem Informasi, CRM, Iterasi, MySQL, PHP

\begin{abstract}
Tour \& Travel is a company engaged in tourism services and services in and foreign services, booking airline tickets, hotel bookings, car rentals, and hajj / umroh services. This company has limited media promotional information, as a result, customers don't know the complete and correct information. In addition, this company can customize it, but not many customers know that. Customer complaints during the trip often do not go directly to the director, but customers always deliver it to tourguide. Development of applications to overcome these problems is to build a website-based customer relationship management information system with the method used is an iterative methodology consisting of the planning phase, problem analysis phase, design phase, implementation phase, and maintenance phase. This application uses the PHP programming language and uses the Notepad ++ program and MySQL as the database. With this application, it is expected to be able to assist in the delivery of information and help companies increase customer loyalty, attract new customers and retain existing customers in order to help each marketing process carried out by the company.
\end{abstract}

Keywords: Information Systems, CRM, Iteration, MySQL, PHP 


\section{PENDAHULUAN}

Customer Relationship Management (CRM) merupakan strategi yang digunakan untuk mempelajari lebih lanjut tentang kebutuhan dan sifat pelanggan dalam mengembangkan hubungan yang lebih dekat dengan pelanggan. CRM juga dapat diartikan sebagai fungsi terintegrasi dan strategi penjualan, pemasaran dan pelayanan yang bertujuan untuk meningkatkan pendapatan dan kepuasan pelanggan. Selain itu CRM juga berkaitan dengan pelanggan dalam suatu perusahaan yang bertujuan untuk meningkatkan akses yang lebih cepat dan kualitas dari suatu proses bisnis yang melibatkan beberapa bidang yaitu bidang pemasaran (marketing), bidang pemesanan (order), dan pelayanan konsumen (customers service) [1].

Pariwisata dalam arti modern adalah merupakan fenomena dari jaman sekarang yang didasarkan atas kebutuhan akan kesehatan dan pergantian hawa, penilaian yang sadar dan menumbuhakan cinta terhadap keindahan alam dan pada khususnya disebabkan oleh bertambahnya pergaulan berbagai bangsa dan kelas manusia sebagai hasil dari perkembangan perniagaan, industri, serta penyempurnaan dari alat-alat pengangkutan [2].

Biro perjalanan (Travel) adalah suatu perusahaan yang memperoleh pendapatan dan keuntungan dengan menawarkan dan menjual produk serta jasa-jasa pelayanan yang diberikannya kepada pelanggannya [3].

PT Arya Media Tour \& Travel merupakan perusahaan yang bergerak di bidang jasa dan pelayanan pariwisata di dalam dan layanan luar negeri, pemesanan tiket pesawat, pemesanan hotel, rental mobil, dan layanan haji/umroh. Perusahaan juga melayani dalam bidang perjalanan wisata yang bersifat komersil yang dapat mengatur dan menyediakan pelayanan bagi seseorang atau sekelompok orang.

Seiring berkembangnya teknologi saat ini mengakibatkan persaingan dalam dunia bisnis pun semakin pesat yang mengakibatkan suatu perusahaan berlomba-lomba untuk dapat menarik minat pelanggan dimana, kualitas pelayanan tetap menjadi sesuatu yang sangat penting, dalam menghadapi pelanggan yang membutuhkan level of excellence yang tinggi. Pelayanan yang bermutu tinggi yang berarti mampu memberikan keselarasan terhadap kebutuhan pelanggan, Secara esensial, baik pelanggan kelas atas, menengah bahkan bawah sekalipun membutuhkan pelayanan yang baik dan bermutu, hanya saja tingkatannya yang berbeda-beda. Jika diamati sesungguhnya inti persaingan saat sekarang ini lebih pada bagaimana perusahaan menyadari betul siapa target.

Dengan adanya teknologi website yang canggih saat ini serta desktop sebagai penghubung antara device dan mengimplementasikan CRM ini kedalam sebuah website pada travel dapat dibuat suatu trobosan baru untuk menampilkan cara memperoleh pelanggan baru (Acquire), meningkatkan hubungan dengan pelanggan dan mempertahankan pelanggan (Retain) yang pada akhirnya akan berjuang pada terciptanya kesetiaan pelanggan. Berdasarkan perkembangan teknologi dan kebutuhan customers akan akses layanan yang cepat dan praktis, maka terdapat konsep CRM berbasis web [4].

Sistem informasi adalah suatu perkumpulan komponen ataupun data yang terdiri dari beberapa sub-sub sistem yang saling berhubungan, bekerjasama dan terorganisasi untuk mengolah komponen atau data tersebut untuk menjadi sebuah informasi yang berguna demi mencapai suatu tujuan [5].

Berdasarkan uraian, maka penulis mengusulkan sistem informasi manajemen hubungan pelanggan pada PT Arya Media Tour \& Travel sebagai media pengelolaan informasi pelanggan dan untuk membantu dalam proses mengelola informasi. Selain itu juga dapat memberikan pelayanan yang maksimal untuk menarik pelanggan dan meningkatkan kepuasaan pelanggan. 


\section{METODE PENELITIAN}

\subsection{Pengumpulan Data}

Untuk memperoleh data primer dilakukan wawancara, observasi, dan kuesioner. Wawancara dilakukan kepada administrasi. Wawancara dilakukan secara langsung dan tidak langsung. Secara langsung dilakukan dengan tatap muka, sedangkan secara tidak langsung dilakukan melalui media telekomunikasi seperti telepon dan percakapan online. Teknik observasi dilakukan untuk mengetahui secara langsung kegiatan dalam penyebaran informasi barang. Sedangkan kuesioner dilakukan ketika sistem informasi manajemen hubungan pelanggan sudah diterapkan untuk mengetahui kegunaan sistem yang sudah dibuat [6]. Tahapan ini merupakan langkah-langkah yang akan dilakukan dalam menyelesaikan masalah yang akan dibahas yang tergambar pada Gambar 1.

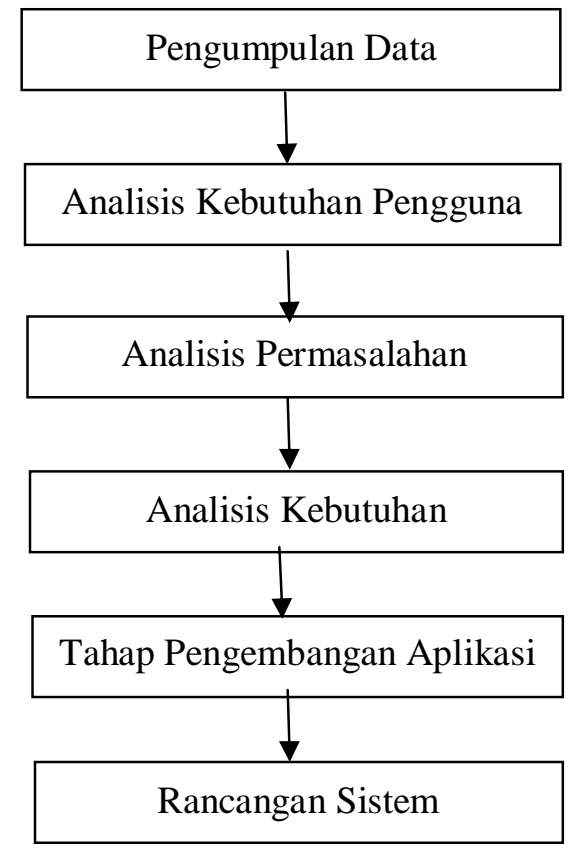

Gambar 1. Langkah-Langkah Penelitian

2.2 Analisis Kebutuhan Pengguna

Hasil analisis kebutuhan pengguna dapat dilihat pada tabel 1 .

Tabel 1. Analisa Kebutuhan Pengguna

\begin{tabular}{|c|l|}
\hline User & \multicolumn{1}{|c|}{ Fungsi } \\
\hline Direktur & $\begin{array}{l}\text { Direktur mempunyai hak akses } \\
\text { untullogin, mengelola data } \\
\text { pengguna, mengelola laporan kritik } \\
\text { saran, laporan paket tour, laporan } \\
\text { pemesanan, laporan paket tour } \\
\text { terbaik, laporan pelanggan terbaik. }\end{array}$ \\
\hline Pelanggan & $\begin{array}{l}\text { Pelanggan mempunyai hak akses } \\
\text { untuklogin, melihat dan memesanan } \\
\text { paket tour, melihat wisata, }\end{array}$ \\
\hline
\end{tabular}




\begin{tabular}{|c|c|}
\hline & $\begin{array}{l}\text { chart,pemesanan, pembayaran, } \\
\text { memberi kritik saran, mengelola } \\
\text { profil. }\end{array}$ \\
\hline Tiket & $\begin{array}{l}\text { Tiket mempunyai hak akses } \\
\text { untuklogin, mengelola data paket } \\
\text { tour, mengelola data wisata, } \\
\text { mengelola data promosi, mengelola } \\
\text { data pelanggan, mengelola data } \\
\text { pemesanan, mengelola data } \\
\text { pembayaran, }\end{array}$ \\
\hline
\end{tabular}

\subsection{Analisis Permasalahan}

Analisis permasalahan menggunakan kerangka PIECES yang terdiri dari Performance, Information, Economics, Control, Eficiency, dan Service. Hasil analisis adalah sebagai berikut [7].

Tabel 2. Analisis Permasalahan Kerangka PIECES

\begin{tabular}{|l|l|}
\hline \multicolumn{1}{|c|}{ PIECES } & \multicolumn{2}{|c|}{ Permasalahan } \\
\hline Performance & - Sulitnya mempromosikan paket tour kepada pelanggan. \\
\hline Information & $-\begin{array}{l}\text { Untuk memberi informasi tentang paket tour yang dapat } \\
\text { disesuaikan, perusahaan kesulitan bagaimana cara untuk } \\
\text { menginformasikan kepada pelanggan bahwa paket tour bisa } \\
\text { disesuaikan keinginan pelanggan. }\end{array}$ \\
\hline Economics & $\begin{array}{l}\text { Perusahan mengeluarkan biaya rutin setiap perubahan harga peket } \\
\text { tour, dikarenakan sistem promosi masih menggunakan brosur dan } \\
\text { telepon }\end{array}$ \\
\hline Control & $-\begin{array}{l}\text { Perusahaan kesulitan mengetahui keluhan, kritik, dan saran dari } \\
\text { pelanggan, yang mengakibatkan perusahaan sulit dalam melakukan } \\
\text { kebijakan/peningkatan pelayanan. }\end{array}$ \\
\hline Efficiency & $-\begin{array}{l}\text { Promosi yang diterapkan di perusahaan masih berbentuk brosur dan } \\
\text { telepon diperlukan biaya untuk pembuatan brosur dan memerlukan } \\
\text { waktu yang cukup lama untuk melakukan proses promosi, } \\
\text { dikarenakan harus mencetak brosur dan memerlukan waktu untuk } \\
\text { menelepon satu persatu pelanggan, dikarenakan harus melihat data } \\
\text { history transaksi terlebih dahulu. }\end{array}$ \\
\hline Service & $\begin{array}{l}\text { Pelanggan merasa terbebani untuk datang langsung ke perusahaan } \\
\text { untuk mendapatkan informasi secara detail mengenai paket tour. }\end{array}$ \\
\hline
\end{tabular}

\subsection{Analisis kebutuhan}

Pada analisis kebutuhan ini dapat diuraikan kebutuhan fungsional dan kebutuhan non-fungsional dari sistem yang akan dibangun.

1. Kebutuhan Fungsional

Use case diagram merupakan suatu permodelan untuk mendeskripsikan kebutuhan sistem terutama aktor yang akan menggunakan sistem, sehingga segala persyaratan sistem yang baik dapat tergambarkan. Dengan teknik use case, fungsi dapat digambarkan apa saja yang ada di dalam sistem dan siapa saja user yang berhak menggunakan sistem tersebut [8]. Pada Use case diagram yang telah dibuat terdapat 46 use case dan 3 aktor. Use case diagram pada Sistem Informasi Manajemen Hubungan Pelanggan Pada PT. Arya Media Tour Travel dapat dilihat pada Gambar 2. 


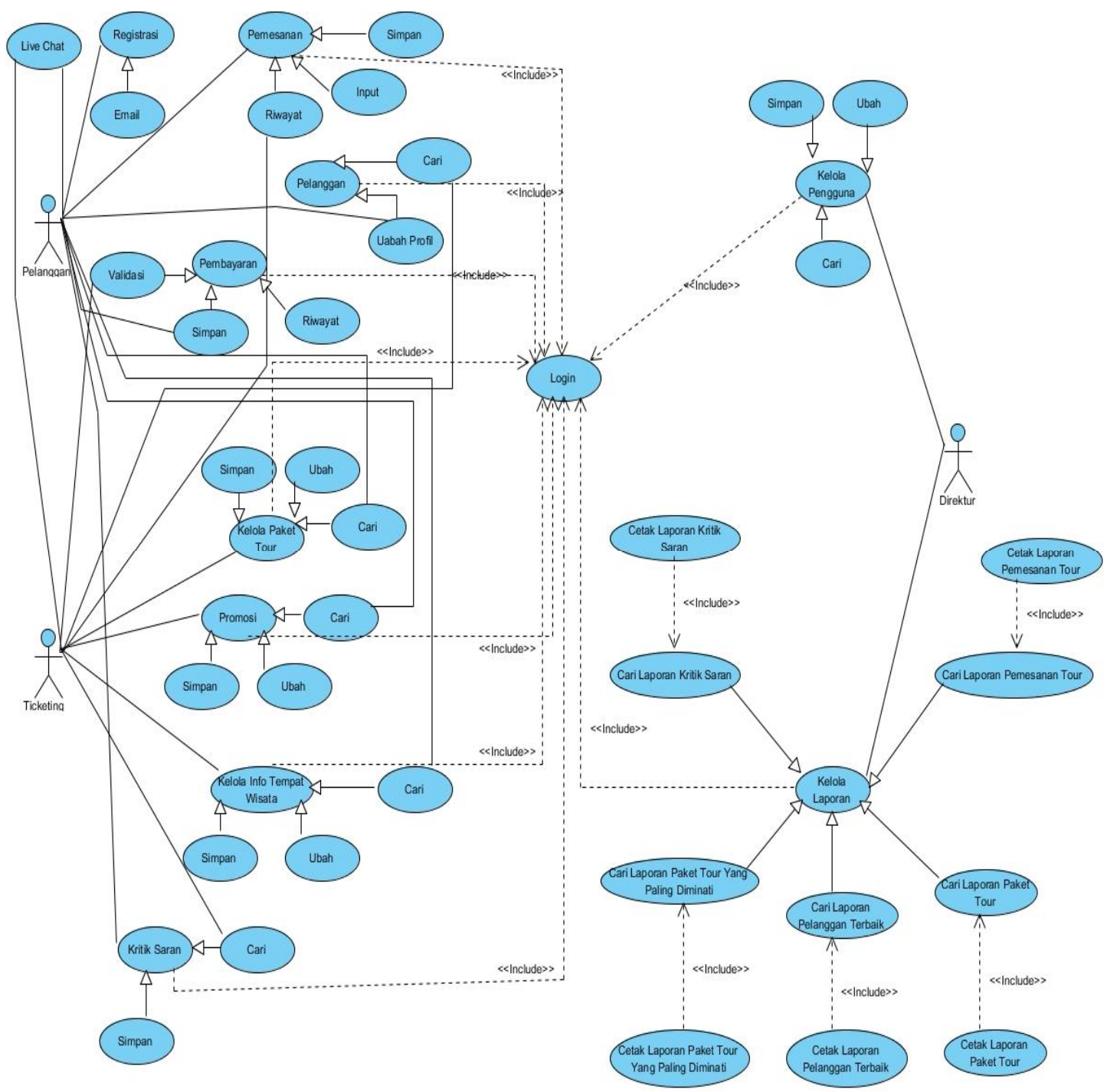

Gambar 2. Diagram Use Case

2. Kebutuhan Non Fungsional

Kebutuhan non fungsional mengacu pada kinerja sebuah sistem maupun kemudahannya. Kebutuhan non fungsional diperhatikan apabila kebutuhan fungsional telah terpenuhi, yang menjadi kebutuhan non fungsional meliputi segi kualitas. Kebutuhan ini harus dimiliki untuk mendukung kebutuhan non fungsional meliputi segi kualitas, antara lain.

1. User

Sistem yang dibangun dapat diakses secara cepat dan mudah serta memiliki tampilan yang user friendly.

\section{Control}

Sistem yang dibangun disertai dengan hak akses sehingga hanya dapat digunakan oleh pengguna yang memiliki hak akses tersebut. 
3. Service

Sistem harus mampu memenuhi kebutuhan pengguna dalam melakukan pekerjaan sehari-hari.

\subsection{Tahap Pengembangan Aplikasi}

Setelah telah menganalisis kebutuhan dan permasalahan, maka tahap selanjutnya adalah melakukan pengembangan aplikasi atau pengkodean. Aplikasi ini dibuat mengguakan program Notepad++ serta MySQL sebagai basis data. MySQL adalah software atau program database server. Sedangkan SQL adalah bahasa pemogramannya, Bahasa permintaan (query) dalam database server termasuk dalam MySQL itu sendiri [9]. Metodologi yang digunakan adalah metode iterasi yang teridiri dari fase perencanaan, fase analisis masalah, fase perancangan, fase implementasi, dan fase pemeliharaan [10].

\subsection{Rancangan Sistem}

Pada tahap ini, rancangan sistem dibuat menggunakan Data Flow Diagram (DFD), EntityRelationship Diagram (ERD), dan tampilan antar muka aplikasi.

\subsubsection{Data Flow Diagram}

Data Flow Diagram (DFD) adalah representasi grafik yang menggambarkan aliran informasi dan tranformasi informasi yang diaplikasikan sebagai data yang mengalir dari masukan (input) dan keluaran (output) [8]. Terdapat 3 entitas, terdiri dari Ticketing Staff, Pelanggan, Direktur. Terdapat 5 proses, terdiri dari Login, Pendataan, Mengelola Pelanggan, Transaksi Tour, Laporan. Terdapat 8 data store, terdiri dari pengguna, pelanggan, paket tour, tempat wisata, promosi, kritik saran, pemesanan, detail pemesanan.Sistem yang diusulkan pada rancangan sistem dapat diilustrasikan pada Gambar 3. 


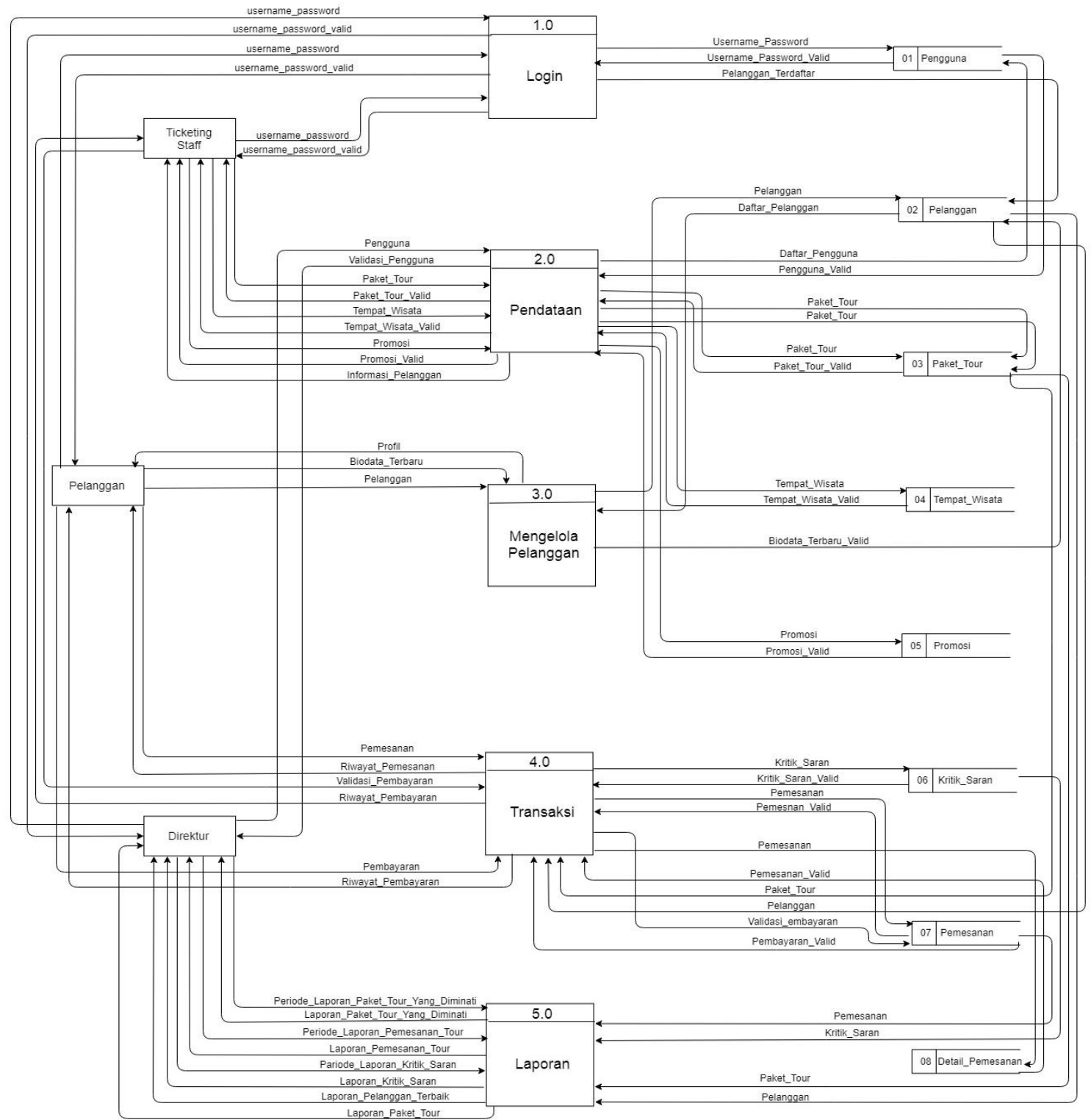

Gambar 3. Data Flow Diagram yang Diusulkan

\subsubsection{Entity Relationship Diagram}

Pada tahap ini dibuat ERD untuk merancang database. ERD adalah pemodelan awal yang dikembangkan berdasarkan teori himpunan dalam bidang matematika untuk pemodelan basis data relasional [8]. Model ERD digunakan untuk menggambarkan hubungan antar entitas di dalam suatu sistem, akan tetapi ERD tidak menggambarkan proses dan aliran data pada sistem. Gambar model ERD dapat dilihat pada Gambar 4. 


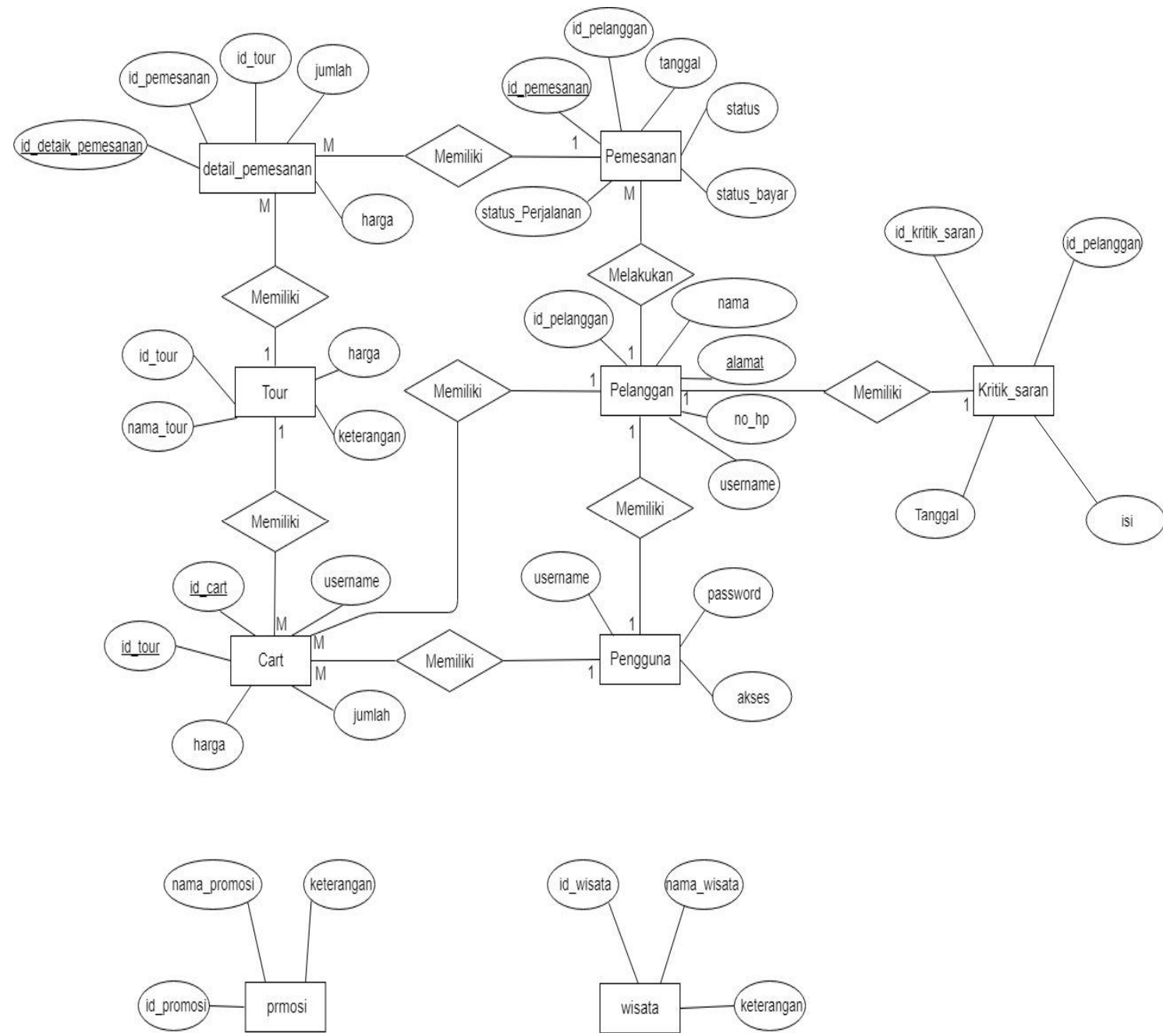

Gambar 4. ERD yang diusulkan

\section{HASIL DAN PEMBAHASAN}

Implementasi merupakan suatu perwujudan/penerapan dari rancangan sistem yang telah dibuat kedalam suatu program sehingga fungsi dari masing-masing proses akan terlihat [9]. Pembahasan terhadap hasil penelitian mengenai sistem informasi manajemen hubungan pelanggan pada PT. Arya Media Tour \& Travel berbasis website yang diperoleh disajikan dalam bentuk uraian teorik secara kualitatif. Hasil dan pembahasan sistem informasi manajemen hubungan pelanggan PT. Arya Media Tour \& Travel berbasis website sebagai berikut.

\subsection{Tampilan Antarmuka Home}

Berikut ini merupakan tampilan antarmuka dari tampilan Home. Semua pengguna akan melihat tampilan ini jika memasuki halaman website PT Arya Media Tour \& Travel. Di halaman ini pengguna dapat melihat daftar paket tour yang ditawarkan dan daftar tempat wisata, berserta harga paket tour. Tampilan antarmuka Home dapat dilihat pada Gambar 5, yaitu sebagai berikut. 


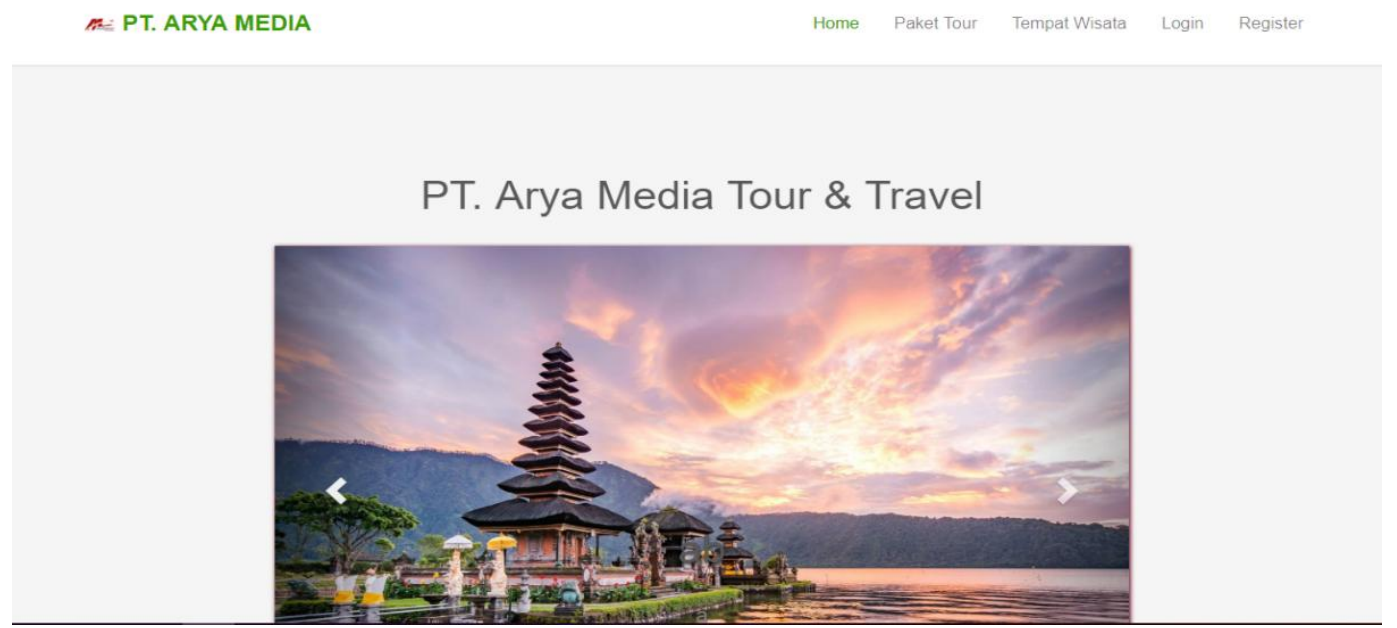

Gambar 5. Form Tampilan Halaman Awal

\subsection{Tampilan Antarmuka Login}

Berikut ini merupakan tampilan antarmuka dari tampilan Login. Pengguna dapat masuk ke dalam website dengan menginputkan username dan password yang telah dimilikinya dengan benar. Setelah berhasil masuk, pengguna akan dialihkan ke halaman web masing-masing sesuai dengan jabatan yang telah didaftarkan. Ticketing akan masuk ke halaman tampilan ticketing beserta hak aksesnya, Pelanggan akan ke halaman tampilan Pelanggan, dan Direktur akan masuk ke halaman tampilan Direktur. Tampilan antarmuka Login dapat dilihat pada Gambar 6, yaitu sebagai berikut.

1.: PT. ARYA MEDIA

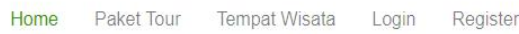

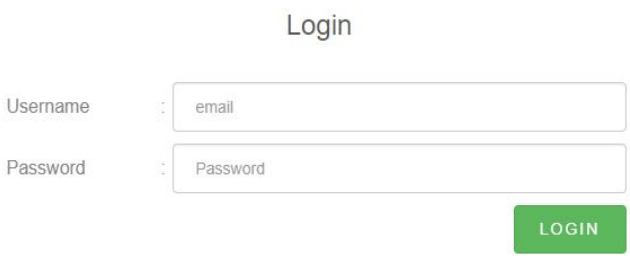

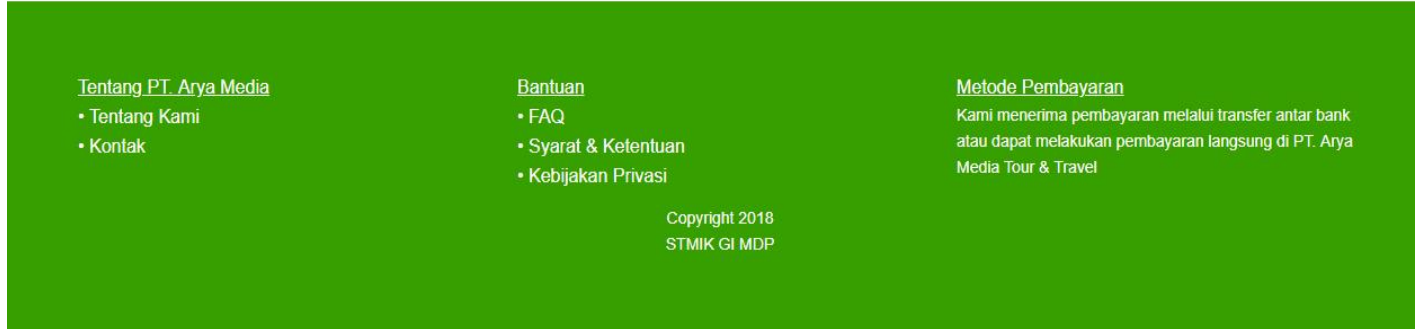

Gambar 6. Form Tampilan Halaman Login

\subsection{Tampilan Antarmuka Menu Utama Pelanggan}

Berikut ini merupakan tampilan antarmuka dari menu utama Pelanggan dari aplikasi. Menu Utama Pelanggan akan tampil setalah user sukses melakukan login ke aplikasi. Ketika user selesai login, maka tampilan menu utama Pelanggan yang muncul berisi menu Home, Paket Tour, Wisata, Cart, Pemesanan, Pembayaran, Profil. Tampilan antarmuka menu utama Pelanggan dapat dilihat pada gambar 7, yaitu sebagai berikut.

Hakim et, al (Sistem Informasi Manajemen Hubungan Pelanggan Berbasis Web Pada PT. Arya Media Tour \& Travel) 
12: PT. ARYA MEDIA Home Paket Tour Wisata Cart Pemesanan Pembayaran Profil $\vee$ Logout

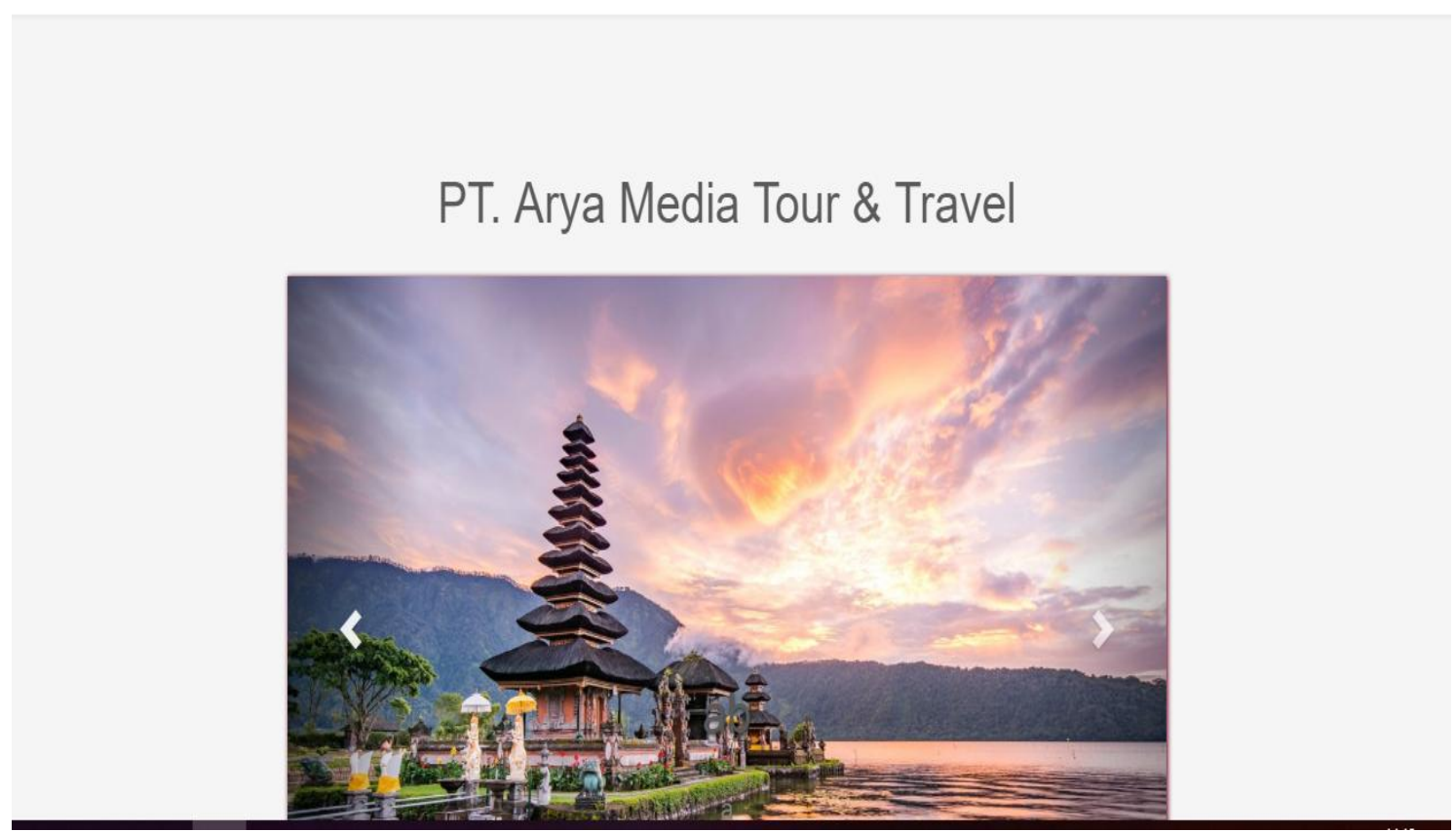

Gambar 7. Form Menu Utama Pelanggan

\section{Paket Tour}

Masukkan pencarian berdasarkan nama Tour atau harga Tour.
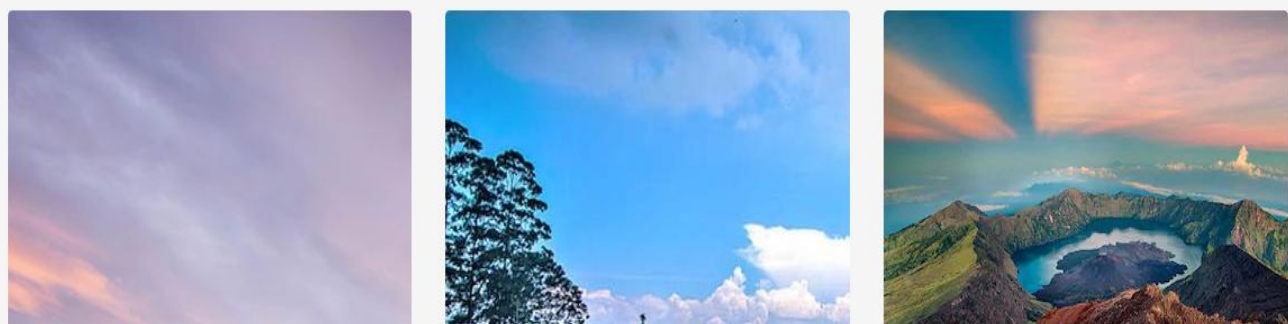

Gambar 8. Form Menu Paket Tour Pelanggan

\subsection{Tampilan Antarmuka Menu Utama Ticketing}

Berikut ini merupakan tampilan antarmuka dari menu utama ticketing dari aplikasi. Menu utama ticketing akan tampil setelah user sukses melakukan login ke aplikasi. Ketika user selesai

Hakim et, al (Sistem Informasi Manajemen Hubungan Pelanggan Berbasis Web Pada PT. Arya Media Tour \& Travel) 
login, maka tampilan menu utama ticketing yang muncul berisi Tour, Wisata, Promosi, Pelanggan, Pemesanan, Pembayaran. Tampilan antarmuka menu utama ticketing dapat dilihat pada Gambar 9, yaitu sebagai berikut.

2.: PT. ARYA MEDIA

\section{PT. Arya Media Tour \& Travel}

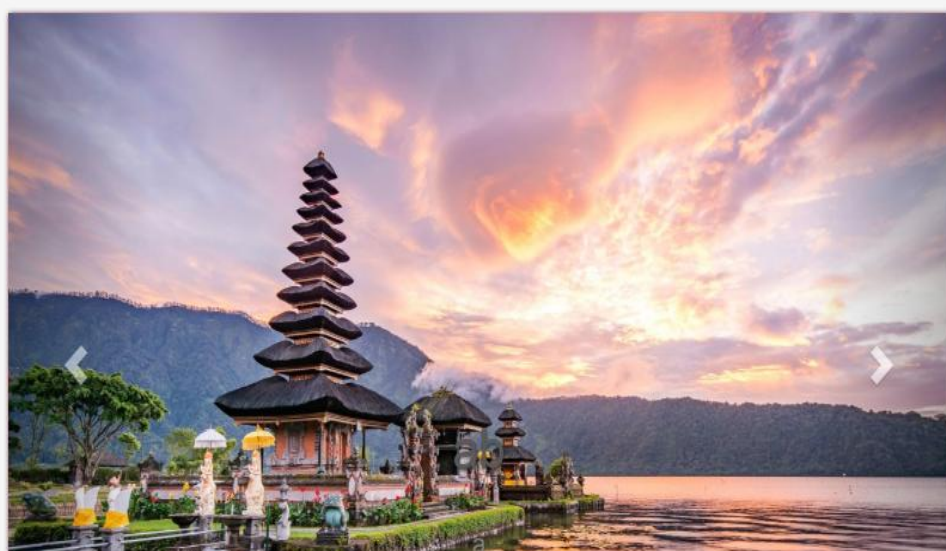

Gambar 9. Form Menu Utama Tiket

MT. ARYA MEDIA Tour Wisata Promosi Pelanggan Pemesanan Pembayaran Ubah Password Logout

Paket Tour

\begin{tabular}{|c|c|c|c|c|c|}
\hline \multicolumn{6}{|l|}{ Nama Paket Tour } \\
\hline Masukkan Nama Tour & \multicolumn{3}{|c|}{ Show 10 entries } & \multicolumn{2}{|l|}{ Search: } \\
\hline Harga & No & Nama & Harga & Keterangan & Aksi \\
\hline Masukkan harga tour & 1 & $\begin{array}{l}\text { Bali } 4 \text { hari } \\
3 \text { malam }\end{array}$ & 4000000 & termasuk hotel makan dan tempat wisata & $\begin{array}{c}\text { Gambar } \\
\text { Edit }\end{array}$ \\
\hline Keterangan & \multirow[t]{2}{*}{2} & \multirow{2}{*}{$\begin{array}{l}\text { BANDUNG } \\
\text { PAKET } \\
\text { FAMILY }\end{array}$} & \multirow[t]{2}{*}{1930000} & \multirow[b]{2}{*}{$\begin{array}{l}\text { Biaya Paket Tour Termasuk :- Transportasi Bus wisata } \\
\text { Ac- - Akomodasi hotel satu kamar berdua sekamar } \\
\text { berdua Hotel the Batara / setaraf - Makan sesuai acara } \\
\text { ( } 2 x \text { B'fast, } 3 x \text { makan siang }+2 x \text { Makan malam )- } \\
\text { Snack lokal dan mineral water di bus - Pemandu Wisata } \\
\text { Tour Leader - Biaya masuk objek wisata - Refreshment } \\
\text { ( daily water on bus ) Biaya Paket Tour Tidak Termasuk } \\
\text { - Pengeluaran pribadi seprti telp, loundry dan minibar - } \\
\text { Tips untuk Guide dan Sopir - Tiket Pesawat }\end{array}$} & \multirow{2}{*}{$\begin{array}{c}\text { Gamba } \\
\text { Edit }\end{array}$} \\
\hline Masukkan Keterangan & & & & & \\
\hline Gambar & \multirow[t]{2}{*}{3} & \multirow[t]{2}{*}{ aB } & \multirow[t]{2}{*}{35} & \multirow[t]{2}{*}{ aB } & \multirow{2}{*}{$\begin{array}{c}\text { Gambar } \\
\text { Edit }\end{array}$} \\
\hline 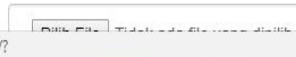 & & & & & \\
\hline
\end{tabular}

Gambar 10. Form Menu Tour Tiket 


\subsection{Tampilan Antarmuka Menu Utama Direktur}

Berikut ini merupakan tampilan antarmuka dari menu utama Direktur dari aplikasi. Menu utama Direktur akan tampil setelah user sukses melakukan login ke aplikasi. Ketika user selesai login, maka tampilan menu utama Direktur yang muncul berisi menu Home, Pengguna dan Laporan. Tampilan antarmuka menu utama Direktur dapat dilihat pada Gambar 11, yaitu sebagai berikut.

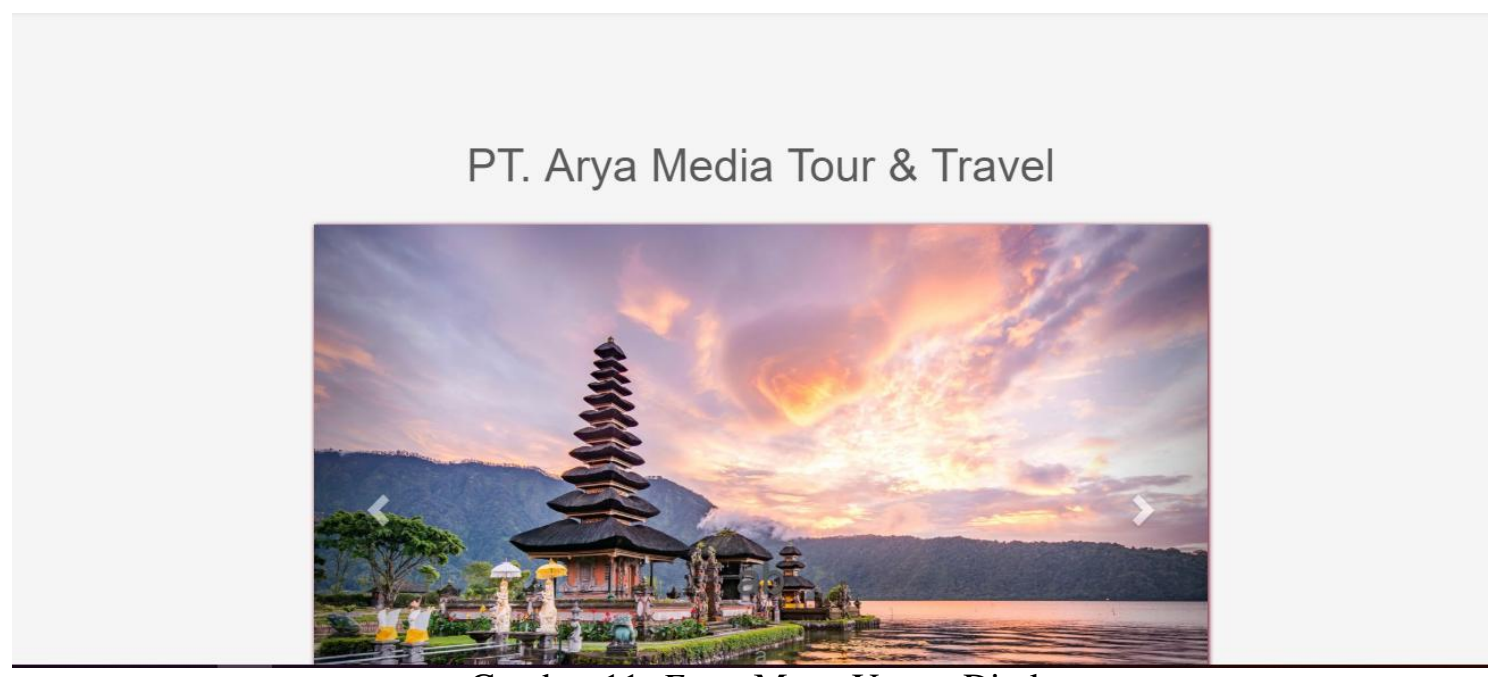

Gambar 11. Form Menu Utama Direktur

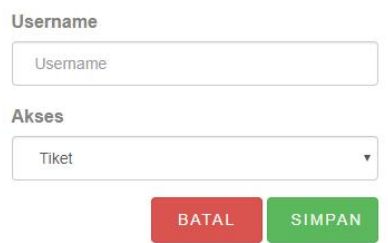

Show 10 entries
\begin{tabular}{|l|l|l|l|}
\hline \multicolumn{1}{|c|}{ Usename } & \multicolumn{1}{c|}{ Search: } & Hak Akses \\
\hline 1 & & Direktur & Edit \\
\hline 2 & direktur & Direktur & Edit \\
\hline 3 & direktur1 & Direktur & Edit \\
\hline 4 & Tiket & Tiket & Edit \\
\hline 5 & tiket1 & Tiket & Edit \\
\hline 6 & tiket2 & Tiket & Edit \\
\hline Showing 1 to 6 of 6 entries & & Previous & 1 \\
\hline
\end{tabular}

Gambar 12. Form Menu Pengguna Direktur 
MT. ARYA MEDIA Pengguna Laporan × Ubah Password Logout

Laporan Kritik \& Saran

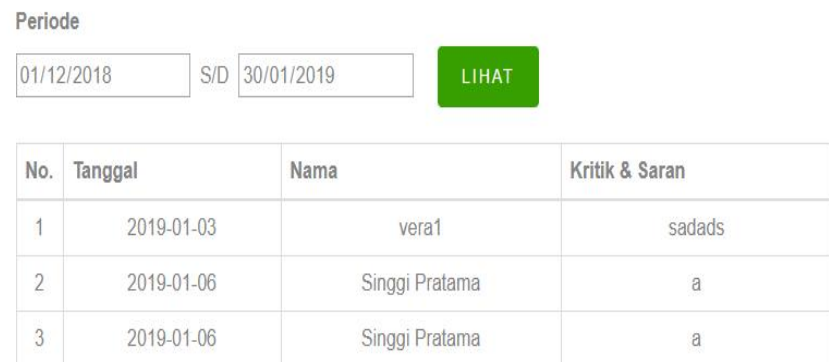

Gambar 13. Form Menu Laporan Kritik Saran Direktur

Laporan Paket Tour

\begin{tabular}{|c|c|c|}
\hline No. & Paket Tour & Harga \\
\hline 1 & Bali 4 hari 3 malam & $4,000,000$ \\
\hline 2 & BANDUNG PAKET FAMILY & $1,930,000$ \\
\hline 3 & aB & 35 \\
\hline 4 & q & 12 \\
\hline
\end{tabular}

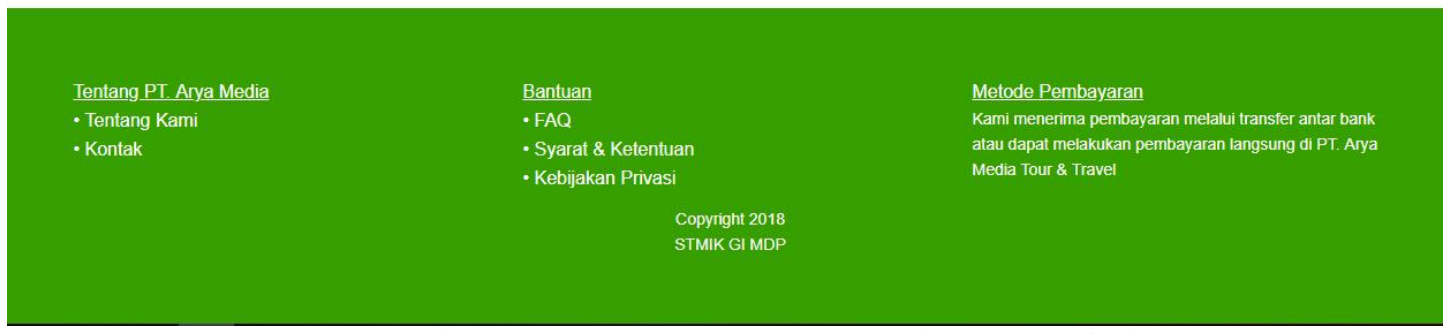

Gambar 14. Form Menu Laporan Paket Tour Direktur

\section{KESIMPULAN}

Berdasarkan hasil pembahasan tentang sistem informasi manajemen hubungan pelanggan pada PT. Arya Media Tour \& Travel, maka dapat disimpulkan sebagai berikut. 1. Sistem ini dapat memberikan informasi secara luas kepada pelanggan.

2. Sistem ini dapat melakukan transaksi pemesanan paket tour dengan melalui website PT. Arya Media Tour \& Travel.

3. Sistem ini dapat memberikan informasi menampilkan pemesanan paket tour yang terbanyak kepada pelanggan. 


\section{SARAN}

Berikut ini merupakan saran yang dapat diberikan kepada perusahaan untuk mengarahkan perusahaan kearah yang lebih baik, yaitu sebagai berikut .

1. Mengembangkan sistem yang serupa dalam bentuk mobile application Android, IOS.

2. Menambahkan fitur SMS Gateway agar lebih memudahkan pelanggan dalam mengakses informasi mengenai promosi.

\section{DAFTAR PUSTAKA}

[1] Buttle, Francis dan Maklan, Stan. 2015, Customer Relationship Management: Consepts and Technologies, Nutech Print Service.

[2] E. Guyer-Freuler. 2013, Handbuch del Weizerichhen Volkswirtschaft, http://wikipariwisata.blogspot.com/2013/06/pengertian-pariwisata.

[3] A, Yoeti Oka. 1996, Pengantar Ilmu Pariwisata, Edisi Revisi, Angkasa, Bandung.

[4] Pramana dian, Ni Luh Manik Sugiarni, Ni Nyoman Harini Puspita. 2015, Implementasi CRM (Customer Relationship Management) Pada Sistem Informasi Travel X Berbasis Web, Jurnal Sistem dan Informatika, Bali.

[5] Sutabri, Tata. 2014,"Pengantar Teknologi Informasi”. Edisi Pertama, Andi, Yogyakarta.

[6] Selva Fithri, Fransiska Prihatini Sihotang. 2018, Layanan Informasi Pembayaran Biaya Kuliah Berbasis SMS Interaktif Pada Sekolah Tinggi XYZ, Junal Sistem dan Informatika, Palembang.

[7] Kohar Kevin, Edwin, Della Oktaviany. 2016, Sistem Informasi Manajemen Hubungan Pelanggan Berbasis Website Pada CV. DEER YOU, Jurnal Sistem dan Informatika, Palembang.

[8] A. S Rosa dan Shalahuddin, M. 2014, Rekayasa Perangkat Lunak Terstruktur dan Berorientasi Objek, Informatika, Bandung.

[9] Nugroho, Bunafit. 2014, Dasar Pemograman Web PHP - MySQL, Informatika, Bandung.

[10] A. S Rosa dan Shalahudin, M. 2011, Modul Pembelajaran Rekayasa Perangkat Lunak Terstruktur dan Berorientasi Objek), Modula, Bandung.

[11] Nugroho, A. 2005, Analisis dan Perancangan Sistem Informasi dengan Metodologi Berorientasi Objek, Informatika, Bandung. 